\title{
Summary of Flipped Classroom Results for Introduction to Engineering Us- ing Google Docs and Interactive Video
}

\author{
Prof. John M. Santiago Jr, Colorado Technical University
}

Professor John Santiago has been a technical engineer, manager, and executive with more than 26 years of leadership positions in technical program management, acquisition development and operation research support while in the United States Air Force. He currently has over 16 years of teaching experience at the university level and taught over 40 different graduate and undergraduate courses in electrical engineering, systems engineering, physics and mathematics. He has over 30 published papers and/or technical presentations while spearheading over 40 international scientific and engineering conferences/workshops as a steering committee member while assigned in Europe. Professor Santiago has experience in many engineering disciplines and missions including: control and modeling of large flexible space structures, communications system, electro-optics, high-energy lasers, missile seekers/sensors for precision guided munitions, image processing/recognition, information technologies, space, air and missile warning, missile defense, and homeland defense.

His interests includes: interactive multimedia for e-books, interactive video learning, and 3D/2D animation. Professor Santiago recently published a book entitled, "Circuit Analysis for Dummies" in 2013 after being discovered on YouTube. Professor Santiago received several teaching awards from the United States Air Force Academy and CTU. In 2015, he was awarded CTU's Faculty of the Year for Teaching Innovations. Professor Santiago has been a 12-time invited speaker in celebration of Asian-Pacific American Heritage Month giving multi-media presentations on leadership, diversity and opportunity at various military installations in Colorado and Wyoming.

\section{Dr. Kathy L. Kasley P.E., Colorado Technical University}

Kathy Kasley earned her BS in Mathematics from Ursinus College, a Master's Degree in Mathematics at Villanova University, a Master's Degree in Electrical Engineering from the University of Colorado in Colorado Springs, and her Ph.D. in Electrical Engineering from the University of Colorado. Dr. Kasley is a Professional Engineer, and has a Consultant-Evaluator for the Higher Learning Commission of the North Central Association of School and Universities for over 15 years. Dr. Kasley has taught mathematics and Engineering at high school, and at the university level for over 25 years. She has served as an instructor, academic adviser, ADA student counselor, and dean or chair of Engineering.

\section{Dr. Jing Guo, Colorado Technical University}

Dr. Jing Guo is a Professor in Engineering Department at Colorado Technical University. She is the course director in circuits and electronics area. She taught variety of underrated and graduate courses including capstone design in Electrical and Computer Engineering area. 


\title{
Summary of Flipped Classroom Results for Introduction to Engineering Using Google Docs and Interactive Video
}

\author{
John Santiago, Jr., Ph.D., Kathy Kasley, Ph.D., and Jing Guo, D.Eng. \\ Colorado Technical University (CTU), College of Engineering, Colorado Springs, CO
}

\begin{abstract}
While the College of Engineering $(\mathrm{CoE})$ is expanding existing engineering courses to online delivery for adult students, the $\mathrm{CoE}$ has a strong commitment to maintain the student-centered focus, and active learning strategies that have enabled success despite the multiple external student commitments.

The strategic plan was to leverage the experience of the full-time faculty to jointly develop modules for the freshman introductory course, Introduction to Engineering. The flipped classroom model seems to be a consistent extension of the existing classroom practice of providing theory in brief introductions, followed by significant classroom practice in problem solving. Once developed, the course was initially offered to students who met on campus, using the online modules. The time in the classroom was used to identify unforeseen issues and bugs that impeded student learning, and to model synchronous "chats" to answer questions and provide students the opportunity to share solutions that would be included in online course delivery. Grading results and course surveys were used to assess and improve the effectiveness of the flipped classroom through sequential course offerings.

The paper summarizes the results of the flipped classroom ${ }^{1-3}$ and its implementation using Google Docs and interactive video ${ }^{4}$. Several topics are briefly discussed to improve the instructional design. Cognitive Load Theory ${ }^{5-7}$ provides rationale for the positive student experience, and numerous tips and studies on the use of video with interactions have been explored by academia and industry ${ }^{8-14}$. These studies show that adding interactions to the multimedia content improves student engagement, retention and many other benefits.
\end{abstract}

\section{Background}

The University serves the needs of adult students who have multiple commitments, such as fulltime work, families, military and financial obligations not typical of the traditional student. Other colleges within the University have fully online degree programs that allow students to increase progress and minimize disruptions. The student population at the College of Engineering consists mostly of adult learners currently attending day and evening classes. The classes are usually 2-3 hours long meeting twice a week. In these face-to-face classrooms, the College of Engineering uses an active learning approach ${ }^{1,2}$ to encourage higher-levels of thinking. Long lectures have been replaced with short 5-15 minute presentations followed by student-centered problem-solving activities.

To provide additional educational opportunity, the College of Engineering (CoE) initiated an exploration of online delivery of existing engineering courses. The CoE felt a strong 
commitment to maintain the student-centered focus, and active learning strategies that had been observed to support the non-traditional student. Like the active-learning approach, the flipped classroom approach also targets higher-levels of thinking. Before coming to class, students must do assigned readings, watch short videos, and complete a series of assessment questions. These assignments are intended to prepare students for the weekly lab experiments when they arrive in class.

The plan was to leverage the experience of the full-time faculty to jointly develop modules for the freshman introductory course, Introduction to Engineering. Once developed, the course was initially offered to students who met on campus, using the online modules. The time in the classroom was used to identify unforeseen issues and bugs that impeded student learning, and to model synchronous "chats" that would be included in online course delivery to answer questions and provide students the opportunity to share solutions. Materials generated were: over 70 YouTube videos about digital and analog electronics to be viewed by students before coming to class, weekly online quizzes (multiple choice, true-false and fill-in-the-blanks), and weekly lab preparations that support active learning. When students come to class, they perform weekly lab assignments. Because labs require students to collaborate in teams, the College of Engineering identified several challenges for delivering the course fully online in the future ${ }^{3}$. The paper will summarize the results of the flipped classroom and its implementation using Google Docs and interactive video for EE110.

Grading results and course surveys were used to assess and improve the effectiveness of the flipped classroom over several course offerings. Various technologies include: (1) using word document with links to YouTube videos followed by with quiz questions in the first offering; (2) adding Google Docs (or Google Forms) with embedded YouTube Videos and quizzes in the next class session; and (3) including both Google Docs and interactive videos in the third. End-ofCourse Surveys consistently show that the students enjoyed the weekly hands-on labs. After the third class offering, an additional survey of student experience with the new technologies was conducted. The results reflected a positive student experience with the course delivery.

\section{EE110 Course Description and Objectives}

Introduction to Engineering, EE110 provides the beginning engineer with fundamental knowledge and skills associated with the electrical or computer engineering professions. It will introduce common electronic components, basic circuit configurations, and laboratory instruments. Bench practices and lab reports will be introduced along with computer aided analysis. The objectives of the course expect students to systematically solve problems; demonstrate safe habits, identify and apply electronic theory, circuits components, and equipment; and identify and apply basic logic gates. 
Table 1 illustrates the lab assignments that the students must complete during class. Before coming to class, the students must watch the videos and complete the weekly quizzes. Otherwise, the student may have trouble completing the lab assignments each week. Minimal or no lecture is presented when students arrive in class. However, student questions are addressed in class. It is expected that students will be more responsible for their own learning. The hardware and its associated software are described in elsewhere [3].

In 2015, a YouTube channel was created to store 70-plus short videos. Figure 1 is a screenshot of the channel.

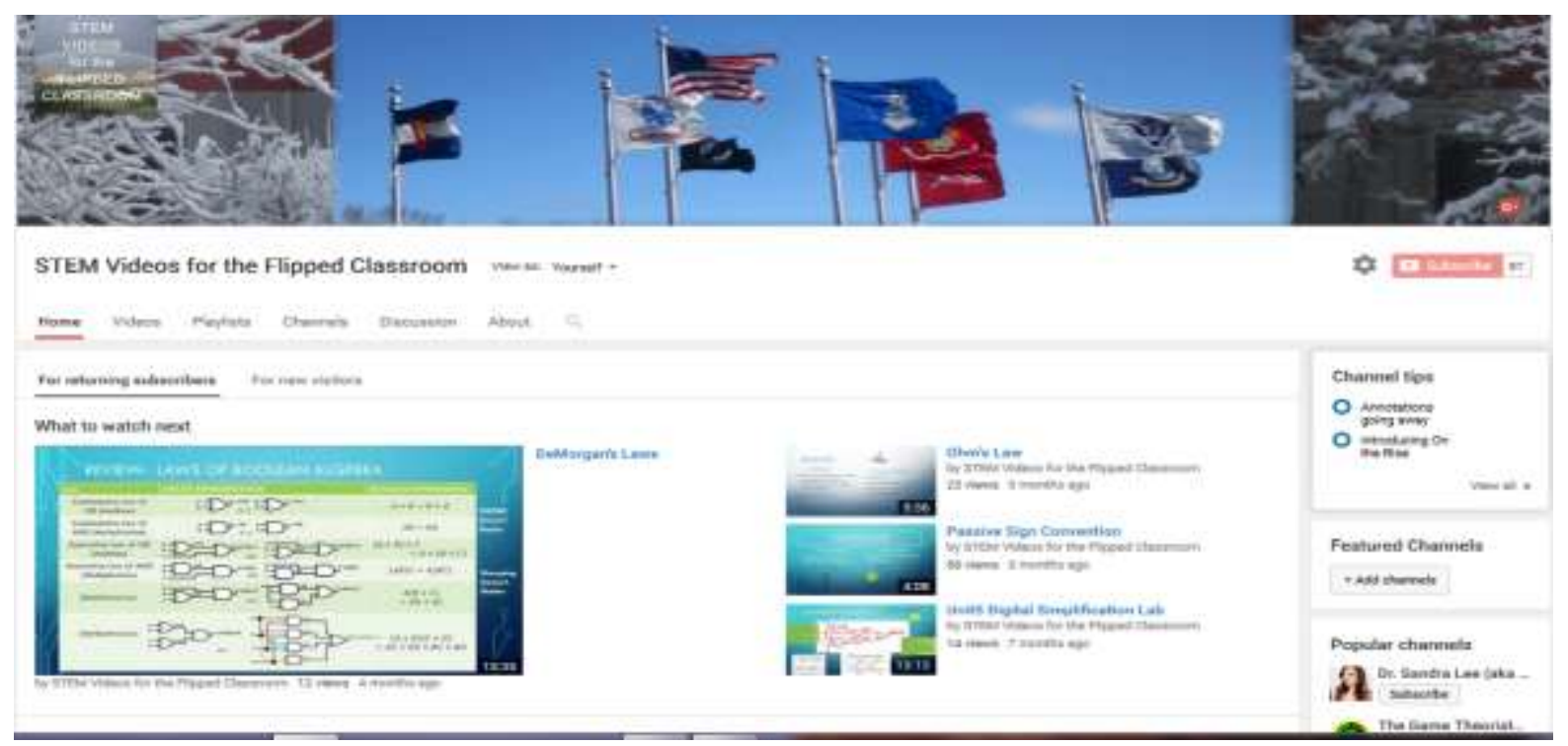

Figure 1. College of Engineering Channel: "STEM Videos for the Flipped Classroom"

\section{Summary of Results Using the Flipped Classroom Approach for Winter 2016 to Fall 2016}

Table 2 shows the results of the grade distribution for the flipped classroom when compared to the traditional face-to-face classroom for course offerings of EE110. The left column shows the 


\begin{tabular}{|c|c|c|c|c|c|c|c|}
\hline & Fall2014 & Win2016 & Sum2016 & Fall2016 & Fall2014 & Spr2015 & Fall2015 \\
\hline A & 5 & 3 & 1 & 3 & 1 & 2 & 3 \\
\hline B & 2 & 1 & 2 & 1 & 4 & 2 & 5 \\
\hline C & 1 & 1 & 1 & 1 & 4 & 1 & \\
\hline D & & 1 & 1 & & & & \\
\hline $\mathbf{F}$ & 1 & 3 & 2 & 2 & & & \\
\hline w/o F & 90.6 & 85.5 & 83.0 & 88.8 & 82.7 & 88.1 & 87.7 \\
\hline$w / F$ & 85.2 & 66.7 & 67.0 & 70.7 & & & \\
\hline Instructor & 1 & 1 & 1 & 1 & 2 & 3 & 4 \\
\hline DELIVERY & Ground & Flip & Flip & Flip & Ground & Ground & Ground \\
\hline
\end{tabular}

Table 2. Summary of Grade Percentages from 2014 Fall Quarter to 2016 Fall Quarter

grade distribution, average percentage grade for the class, number of instructors, and delivery method. The grades were averaged both with and without including students who received an F. Instructor 1 (one of the authors) taught all the flipped classrooms during 2016 and traditional face-to-face (or ground) course during Fall 2014 quarter.

During 2014 and 2015, adjunct instructors taught the ground sections shown in the last three columns. The percentage grades found in the last three columns serve as a comparison with the flipped classroom. In the flipped classroom approach, there is an increase in the number of Fs when compared to the ground courses.

Table 2 also shows the average percentage grade (highlighted in yellow) when removing students with F-grades. For students who passed the course, the results show that the flipped classroom approach was effective. The results from the 2016 Fall Quarter are comparable with the 2014 Fall Quarter results. Based on student feedback, the multimedia and interactive content appear to be satisfactory in preparing students to conduct the labs

The Fs resulted primarily from non-attendance in class and no work submission. The authors further investigated the increase in the number of students receiving Fs. The results are summarized in Table 3. 


\begin{tabular}{|c|c|l|}
\hline Attendance & $\%$ Grade & \multicolumn{1}{c|}{ Comments } \\
\hline 20.0 & 7.6 & lack of attendance \\
\hline 47.6 & 12.4 & $\begin{array}{l}\text { lack of attendance and large number of assignment } \\
\text { receiving a grade of 0 points }\end{array}$ \\
\hline 50.0 & 37.0 & large number of assignments receiving a grade of 0 points \\
\hline 60.0 & 23.7 & large number of assignments receiving a grade of 0 points \\
\hline 70.0 & 34.1 & large number of assignments receiving a grade of 0 points \\
\hline 71.4 & 38.6 & large number of assignments receiving a grade of 0 points \\
\hline 80.0 & 36.1 & large number of assignments receiving a grade of 0 points \\
\hline
\end{tabular}

Table 3. Attendance and percentage grades from students who received an F

These results are consistent with the 2016 Winter Quarter survey ${ }^{1,2}$. These students did not like the flipped classroom. The flipped classroom requires the student to take on more responsibility, including: (1) viewing the multi-media content and completing assigned homework, (2) taking the frequent assessment activities and (3) performing weekly hands-on experiments. Students who are more comfortable with the traditional face-to-face instruction may not be prepared for these responsibilities.

For students who performed the assigned tasks, the multimedia content and assessment activities prepared them to perform weekly lab experiments.

In addition, Google Docs was used to record the assessment activity and to reduce the administrative burden associated with frequent testing. Figure 2 shows a screenshot of Google Docs. In this example, Figure 2 attempts to show a series a video followed with short quizzes. 


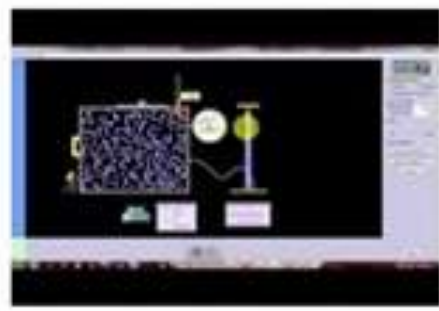

\section{Short YouTube Video}

14. Voltage can be viewed as providing electrical pressure to move electrons found in a cireuit.
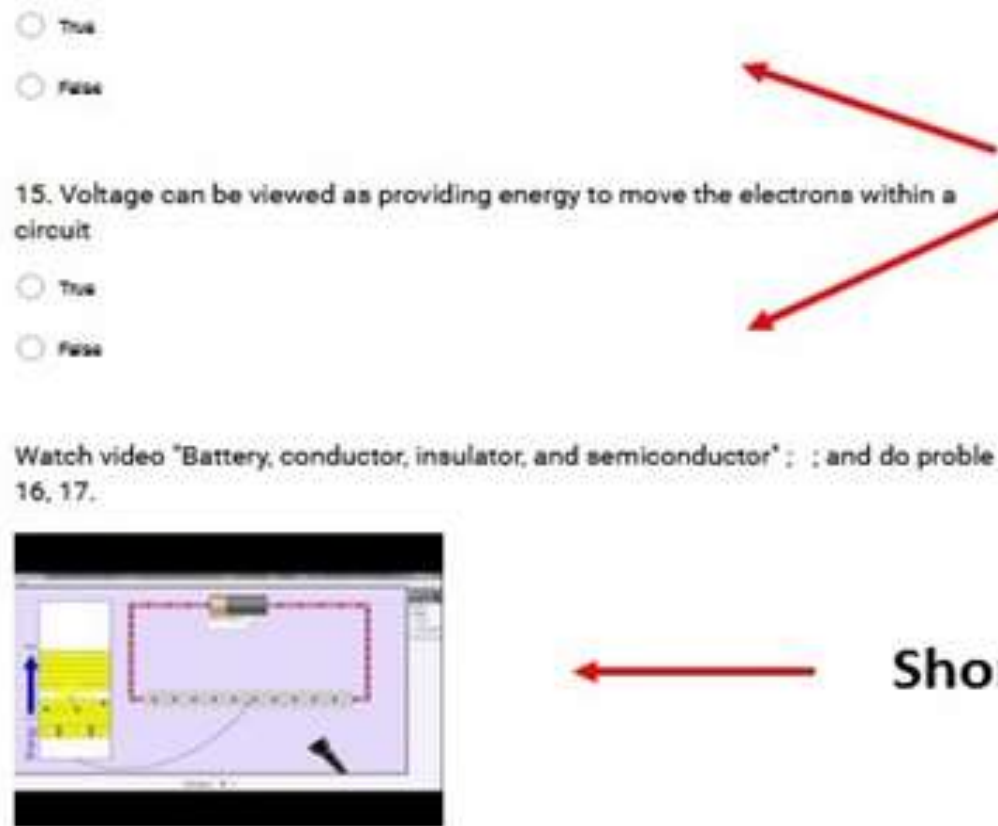

Quiz Questions

15. Voltage can be viewed as providing energy to move the electrone within a

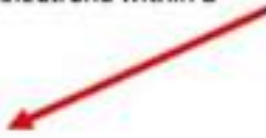

\section{o}

\section{Short YouTube Video}

16. A conductor has a large number of free electrons.

Figure 2. Screenshot of Google Docs with embedded YouTube videos and quiz questions

The authors wanted students to interact more with the videos to increase engagement. For example, embedded questions were posted on top of the videos to simulate a conversation with e-learners. Interactions were added without redoing the 9 hours of 70-plus videos using a tool described in the next section. Preliminary results from the use of interactive video and Google Docs are shown on Table 2 in the column labelled 'Fall2016'. Student were positive about interactive video as well as the delivery of multimedia content using Google Docs. These results of student feedback are described later in the paper. 


\section{H5P - An Open-source and Free Authoring Tool ${ }^{4}$}

$\mathrm{H} 5 \mathrm{P}$ is a free and easy-to-use e-learning authoring suite, which was used to improve student engagement with the course material. H5P is based on HTML 5 which is mobile friendly, as well as supported on various devices ${ }^{4}$. Table 4 lists the various interactive multi-media content found in H5P. Although not as versatile as other tools, it eliminates the cost for experimentation. Some services can cost at about $\$ 65,400$ per year for a platform version. A YouTube video can be enhanced with a variety of questions, text, pop-ups, and quizzes. Using his approach will make the content more interactive.

In addition to interactive video, $\mathrm{H} 5 \mathrm{P}$ has numerous other content types to deliver interactive course material ${ }^{4}$. The authoring tool has been designed so that the content can be shared and reused. The types of content include widgets such as: games, multimedia, questions and social

\begin{tabular}{|l|l|}
\hline \multicolumn{1}{|c|}{ Multimedia Content Type } & \multicolumn{1}{c|}{ Description } \\
\hline Interactive Video & Create videos enhanced with interactions \\
\hline Course Presentation & Produce interactive slides engaging students to act \\
\hline Image Hotspots & Overlay an image with multiple hotspots to provide info \\
\hline Timeline & Create a timeline of events with multimedia \\
\hline Find the Hotspot & Create hotspots for students to find \\
\hline Iframe Embedder & Embed a url or a set of files \\
\hline Appear.in & Add a video chat to a web page \\
\hline Chart & Generate bar and pie charts \\
\hline Impressive Presentation & Create a slideshow with parallax effects \\
\hline Collage & Create a collage of multiple images \\
\hline
\end{tabular}

Table 4. Samples of Multimedia Content Widgets in $\mathrm{H}^{4} \mathrm{P}^{4}$

media. One widget is "course presentation". An instructor creates slides that are interactive. Here, the educator can add text, audio, video and more. The instructor can even add gamification such as a board game. In this case, the user answers quiz questions to complete each level. The instructor can develop a question set. The set can be a sequence of tasks engaging the user with multiple choice, drag and drop and fill in the blanks. Flash cards are also valuable so that learners can insert text corresponding to an image ${ }^{4}$. These content types provide a variety of interactive teaching modules to maintain student interest.

\section{Example Using H5P's Interactive Video}

Figure 3 provides an example of what is meant by an interactive video. The left screenshot shows the display of an interactive view before a student presses a knowledge check button. When a knowledge check activity appears on the video, it automatically pauses. The pause signals the student to act. As shown on the bottom of the left screenshot, the knowledge checks appear throughout the video at various times. This provides the student a level of anticipation which engages the learner. 
A Demonstration of Measuring Current Using PHET

Simulations

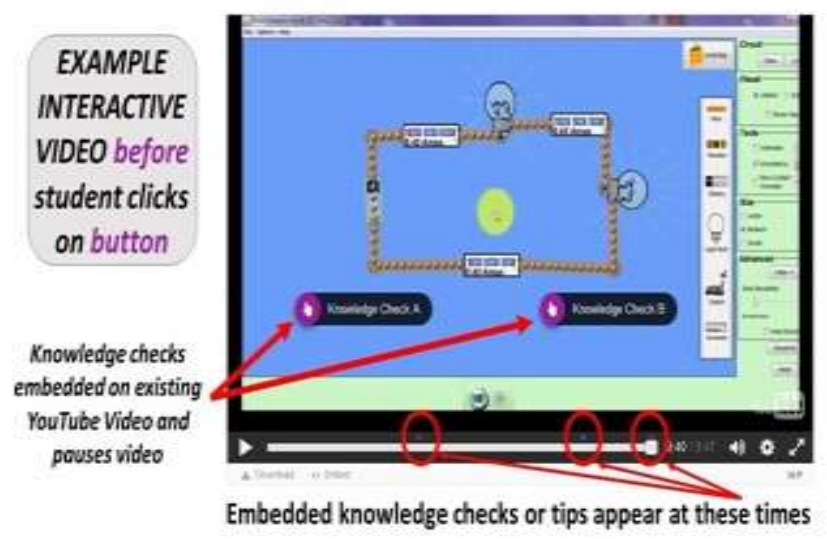

A Demonstration of Measuring Current Using PHET Simulations
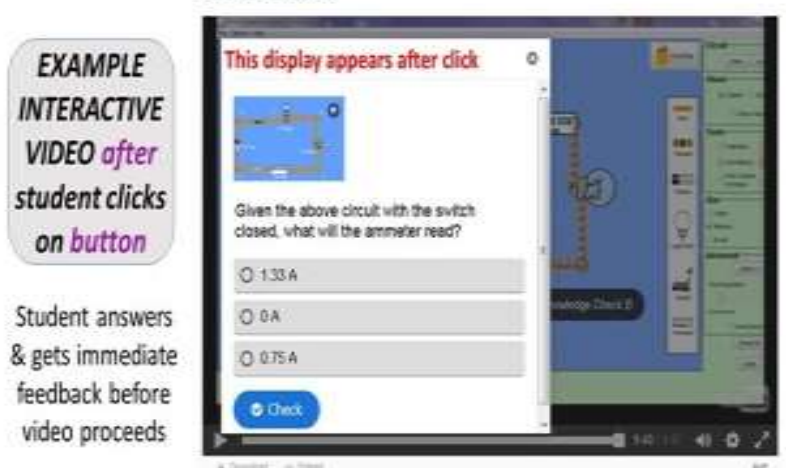

Figure 3. Example of interactive video of screenshots before and after student clicks on knowledge check button

The right illustration of Figure 3 shows the display after the student clicks on the button. The student must respond to the learning activity. After answering the question, the e-learner gets feedback. Also, the answers shown here are randomize in terms of the order. For example, $1.33 \mathrm{~A}$ shown on the top of the choices may appear on the bottom $0.75 \mathrm{~A}$ the next time the video is played. This random feature forces the learner to pay attention if the student decides to replay the video for review.

\section{Fall Quarter Results - Google Docs and Interactive Video}

To assess the teaching effectiveness of the flipped classroom using Google Docs and interactive video, results of the survey are shown in Tables 5 and 6. Table 5 lists the quantitative ratings of four questions. Overall,

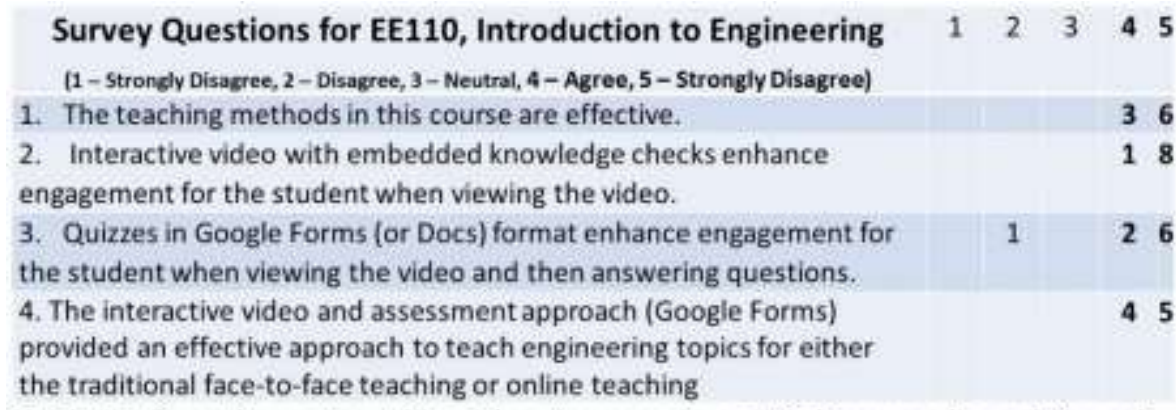

Table 5. Questions about Teaching Approach and Delivery using a Flipped Classroom Pedagogy

the results of Table 5 show the teaching approach was effective and a positive student experience. In Table 6 , student comments are positive and consistent with previous survey results ${ }^{1,2}$. Although the sample size is small, the comments are instructive and are discussed next.

Question 1: The teaching methods in this course are effective. In Table 6, the frequent assessments help reinforce the concepts in the lecture per one student comment. Students like the rewind feature to view the video when they do not understand the topic. The flipped 
1. The teaching methods in this course are effective:

The evaluations through the video really help to reinforce concepts covered in the lecture.

I liked the way that the lectures focused on just one or two points and thoroughly explained them. I also liked that if there was a topic that I did not understand immediately I could rewind the video and view the material again.

The teaching methods were as effective as they could be with out a face to face.

I enjoy the quiz style for the extra credit as well

2. Interactive video with embedded knowledge checks enhance engagement for the student when viewing the video: More video lectures should be setup like this.

I find that when I watch a long video or a video lecture it is easy for my mind to wander or get distracted. I felt that the knowledge check kept my mind from wandering and helped me to focus on the topic main points of the topic.

The interactive part of the video greatly helps with keeping you engaged with the material.

3. Quizzes in google forms format enhance engagement for the student when viewing the video and answering the questions

The quiz question formats used are excellent and easy to understand.

I found that just knowing that there was going to be a quiz made me want to make sure I understood the topic at hand. I also thought that to see the material and then be given a question about it made sure that I was understanding what the main points were and that I understood the types of examples to display my knowledge. I also liked having the answers for questions that I missed so I could go back to the video or look in the book to find out how to get the correct answer. This gave me much more confidence in my understanding of the material.

4. The interactive video and assessment approach (Google Forms)provided an effective approach to teaching engineering topics for either the traditional face-to-face teaching or online teaching:

Both online and ground classes should have access to these videos. Doing so could allow more time for in class discussions on more complex topics.

This is definitely helpful since I have taken the EE110 and was required to watch the whole video and then answer the questions. I feel putting the questions in the video immediately after the topic is covered helps the user to retain the information better as well as stay engaged.

I thought that the interactive video and assessment approach did provide an effective approach to teaching the topic. I think that watching the videos combined with reading the book and completing homework will give the student a thorough understanding of the topic. I am primarily a ground student and I think that these interactive videos would be a valuable tool for a ground class also. I find that a student can never have enough resources to reinforce the knowledge given in class. If a student is having trouble grasping the concepts of a class fast enough these videos would be invaluable.

The videos would greatlyenhance a traditional class and definitely make online classes a more feasible option for online classes.

Although the google form learning style can be effective, sometimes it is possible for a student to pass without learning the material. Because of this, I believe that the interactive video learning style is more effective.

Table 6. Student Survey on Teaching Methods for 2016 Fall Quarter

classroom approach appears to come close to the face-to-face instruction per second student comment. The frequent knowledge assessment questions are consistent with past studies ${ }^{5-7}$.

Question 2: Interactive video with embedded knowledge checks enhance engagement for the student when viewing the video. In Table 6 , the results show the students significantly liked (8 strongly agree and 1 agree) the interactive video feature to promote engagement. One student 
would like to have more video lectures set up like this. Although the videos are relatively short (5 to 10 minutes as a goal), one student's mind began to wander. A Harvard study about elearning noted this issue about mind wandering ${ }^{8}$ :

"It was surprising how high the baseline tendency to mind-wander is," Schacter said. "In our experiments, when we asked students if they were mind-wandering, they said yes roughly 40 percent of the time. It's a significant problem...It's not sufficient for a lecture to be short or to break up a lecture as we did in these experiments," Schacter said. "You need to have the testing. Just breaking it up and allowing them to do something else, even allowing them to re-study the material, does nothing to cut down on mind-wandering, and does nothing to improve final test performance. The testing is the critical component."

The preliminary results on the 2016 Fall Quarter survey appears to support frequent testing. By adding interactive features in the video, the knowledge checks appear to keep the learners mind from wandering and to focus on the main topic. The embedded knowledge checks were primarily quizzes with true/false, multiple choice and fill-in-the-blanks. Other assessment activities can provide variety and promote higher-level thinking through reflection exercises. In a Brandon Hill Study ${ }^{9}$, interactive videos or training offers 40-60\% less employee time than if the same content was delivered in a classroom.

Interactive videos allow e-learners to control the learning process. With navigation hotspots, the instructor can create a custom video where the viewer can click on linkable text and images that appear in the video. When the learner clicks on a specific area on the video, the learner can go to a different portion of the same video or to an external URL containing new content or interactive assessment tools. The instructor can provide the learner with an embedded menu of bookmarks at the video's beginning allowing them to highlight different parts of the video.

Question 3: Quizzes in Google forms format enhance engagement for the student when viewing the video, and then answering questions. In Table 6, the EE110 students viewed videos without embedded interactions on the video. Students must view the whole video and then answer questions. Although the survey shows that this approach is effective, interactive video approach was more favored. In Google Docs, the questions were easy to understand and excellent, as commented by one student. Another student realized that simply answering quiz questions highlighted key concepts requiring understanding.

Based on this comment, instant feedback on answering questions can further improve the interactive content when a student answers a question incorrectly. This becomes a teaching moment by providing constructive feedback. Presently, the knowledge checks only showed that the answer was either correct or incorrect. In the future, more narrative feedback for an incorrect answer needs to be incorporated as part of continuous improvement. However, even without the constructive feedback, a motivated student will find other resources for the correct answer based on the third comment of Question 4.

Question 4: The interactive video and assessment approach (Google Forms) provided an effective approach to teaching engineering topics for either the traditional face-to-face teaching or online teaching. This question received the most comments with five. In Table 6, it appears 
that the students would be satisfied with the content when the instruction is delivered for either online or traditional face-to-face instruction. The first comment showed that the flipped classroom approach can be used to discuss more advance and complex topics in class which is one of the goals of the flipped classroom. The second comment prefers questions to be embedded within the video to help retain the material and help keep students engaged. The third comment felt that the interactive video would be valuable for ground students as well for reviewing hard-to-grasp concepts. Furthermore, the resources provided to the student allows the student to get a thorough understanding of the topic. The additional resources allow the student to get involved with the content by pulling information instead of just pushing content to the elearner by the instructor. The fourth comment shows that videos not only enhance the traditional ground class but also shows that it may be feasible to teach engineering when it is delivered online.

Finally, the last comment shows that a student can pass the quiz without learning the material which is puzzling and this needs to be investigated. The fact that students can take the preassessment quiz three times may explain this comment. However, the same student commented that the interactive video appears to be preferable than the Google Docs approach. In the future, the engineering department intends to use the University's adaptive learning (AL) software to provide more practice in solving problems by automating and generating random homework problems. For example, random values of circuit components in various circuit configurations can be generated for each student. Students can solve a variety of circuit analysis problems that are different and not repeated for each student using different solution methods. The authors believe that randomizing questions would benefit students to learn the material. The educator could alternate between the two approaches: interactive video and Google Docs. Videos and other course content is intended to prepare students with weekly hands-on lab assignments.

\section{General Course Survey.}

The above survey was new during the Fall 2016 quarter. However, the general survey used in previous quarters was also given to the EE110 students with five of the seven responding to the survey. Table 7 shows the survey results and are consistent with previous surveys. Since the students had to do two surveys, the students were not required to write 2-3 paragraphs for each question as done in previous surveys.

Overall, the students enjoyed the course and hands-on activities along with the associated challenges, especially the soldering tasks. The results show that the instructional design of the course was effective in having students grasp key and challenging concepts needed to pursue other courses in engineering. Using the flipped-classroom approach, the multi-media content prepared the students to perform the weekly hands-on lab experiments by providing a solid understanding of key concepts.

After further research to improve the process of creating content for future courses, the next section provides some guidelines based on extensive studies on efficient e-learning with multimedia ${ }^{5-7}$. 


\begin{tabular}{|c|c|}
\hline \multicolumn{2}{|r|}{ 1. What did I not expect in this course, and was pleasantly surprised to learn/receive? } \\
\hline$\bullet$ & That I made the right choice changing majors. \\
\hline$\bullet$ & I did not expect soldering. I enjoyed soldering. \\
\hline • & Yes \\
\hline$\bullet$ & Soldering training/practice \\
\hline$\bullet$ & soldering skills \\
\hline \multicolumn{2}{|r|}{ 2. What did I expect in this course, and was provided new direction? } \\
\hline$\bullet$ & I expected to get a decent grasp on electronics and engineering and I did. \\
\hline$\bullet$ & I expected to learn binary. I learned binary and hexadecimal. \\
\hline$\bullet$ & Yes \\
\hline$\bullet$ & Boolean algebra solving \\
\hline & $\begin{array}{l}\text { I had } 0 \text { understanding of electricity, and so the content of this course opened my eyes to how much work } \\
\text { goes into the tiniest bits of electronics, and that before this class even the most basic circuit was beyond } \\
\text { my understanding. }\end{array}$ \\
\hline \multicolumn{2}{|r|}{ 3. What did I find in the course that was the most challenging? } \\
\hline$\bullet$ & Soldering. \\
\hline$\bullet$ & The circuit analysis labs were challenging but very interesting. \\
\hline$\bullet$ & In class \\
\hline$\bullet$ & Making good solder connections \\
\hline$\bullet$ & $\begin{array}{l}\text { Boolean Algebra and circuit simplification. The not not of not not of not not times the not not of the not } \\
\text { or not and the nand of yes yes. Will always require extra time for me to parse out. }\end{array}$ \\
\hline \multicolumn{2}{|r|}{ 4. What did I find out that I can use to improve in the next course? } \\
\hline$\bullet$ & Soldering \\
\hline$\bullet$ & How to calculate and measure current, volts, and resistance. \\
\hline$\bullet$ & Interactive videos are awesome \\
\hline$\bullet$ & Boolean algebra operations \\
\hline$\bullet$ & $\begin{array}{l}\text { Stay on top of the work, circuits are actually fairly simple when you use diagrams and truth tables. } \\
\text { Soldering is not only fun, but rewarding. WATCH THE VIDEOS. }\end{array}$ \\
\hline
\end{tabular}

Table 7. General Survey of EE 110, Introduction to Engineering

\section{Continuous Improvement on Content Creation for Future Courses}

Summary of Cognitive Load Theory (CLT). Although the creation and delivery of multimedia content was based on the College of Engineering teaching experience, other research provides a theoretical basis for development of the content. The intent of the research is help establish some guidelines in developing and improving the delivery of instruction for new online instructors. Cognitive Load Theory (CLT) appears to be consistent with the traditional face-toface teaching by the College of Engineering is briefly summarized next.

Cognitive Load Theory provides evidence-based guidelines for designing and delivering instruction that accounts for the limited capacity of working memory ${ }^{5,6}$. CLT also leverages the learning process in human cognition for efficient learning. Table 5 summarizes key principles and guidelines below based on Cognitive Load Theory ${ }^{5,6}$. Space limitations prevent a full and comprehensive discussion of CLT.

In terms of future development and improvement of online courses, the authors will leverage previous teaching experience, the flipped classroom approach, and CLT to better design the instructional content and delivery. Based on student comments, the delivered content for EE 110 appears to follow some of the key principles and guidelines associated with CLT. These elearning principles include: modality principle, split attention, self-explanation/mental rehearsal 


\begin{tabular}{|c|c|}
\hline Principle & Guidelines \\
\hline $\begin{array}{l}\text { Modality } \\
\text { Principle }\end{array}$ & $\begin{array}{l}\text { - Working memory uses separate processing of visual and audio information (dual } \\
\text { encoding) } \\
\text { - Use Visual and Audio Narration for Efficient Use of Resources in Working Memory }\end{array}$ \\
\hline Split Attention & $\begin{array}{l}\text { - Keep diagram/charts and detail explanation on same page to help student focus } \\
\text { attention (avoids split attention) } \\
\text { - Use visual cues and signals when content is complex } \\
\text { - Provide content summaries } \\
\text { - Avoid computer manuals }\end{array}$ \\
\hline $\begin{array}{l}\text { Reversal } \\
\text { Effect }\end{array}$ & $\begin{array}{l}\text { - } \quad \text { Need to consider learner's expertise } \\
\text { - } \quad \text { Experts need less external instructional support } \\
\text { - Novices need worked examples while experts do not }\end{array}$ \\
\hline $\begin{array}{l}\text { Redundancy } \\
\text { Effect }\end{array}$ & $\begin{array}{ll}\text { - } & \text { Avoid narration of slide text (audio and text duplication impedes learning) } \\
\text { - } & \text { Not to be confused with rehearsal or repetition aiding automation }\end{array}$ \\
\hline $\begin{array}{l}\text { Self- } \\
\text { Explanation/ } \\
\text { Mental } \\
\text { Rehearsal }\end{array}$ & $\begin{array}{l}\text { - } \quad \text { Learning activities to transfer new knowledge and skills for long-term retention } \\
\text { - } \quad \text { Mental processing of examples requiring clarification and elaboration } \\
\text { - } \quad \text { Wehearsal for maintenance or elaboration on problem solving instruction } \\
\text { - Worked example/problem pairs more efficient than all-practice lessons }\end{array}$ \\
\hline $\begin{array}{l}\text { Learner } \\
\text { Control }\end{array}$ & $\begin{array}{l}\text { - } \text { Allow learners to control pacing and content } \\
\text { - Teach in segments and modules allowing for repetition or skipping as desired } \\
\text { - Teach support knowledge separately } \\
\text { - Teach Components before full systems }\end{array}$ \\
\hline
\end{tabular}

Table 8. Principles and Guidelines of Cognitive Load Theory ${ }^{5,6}$

(lab activities), and learner control. CLT provides a structure for better module design that can be formulated for efficient online learning as well as for traditional face-to-face instruction. With this background on CLT, using video provides efficient learning, especially when adding interactions on the videos. Further guidelines on the use of interactive video are described next.

Tips on Using Interactive Videos. Christopher Pappas ${ }^{12}$ outlined some key tips when using interactive videos that are summarized below appropriate for the academic environment:

- Keep the interactive videos bite-sized so they are easily digestible and focused on a specific sub-topic

- Keep the focus on the speaker and avoid busy backgrounds and other distractions.

- Include clickable, clear and concise eLearning questions

- Try to include captions while giving complete control to learners so they can pause, rewind and adjust the volume

- Create an online companion guide and avoid computer-type manuals

In the last bullet, the online companion guide was not implemented for EE110 since students did not raise this as an issue. Pandey also outlined similar points to include: hotspots, drag-n-drop and fill-in-the-blanks ${ }^{13,14}$. In addition, the above tips are consistent with extensive and comprehensive studies on multimedia elearning ${ }^{5-11}$. 


\section{Conclusions}

Student surveys show that interactive video from the H5P platform is effective for an introductory course in engineering. During the piloted program, the first approach included watching a series of videos followed with a short assessment activity for each short video. This activity was preparation for a weekly final quiz (using Google Docs) and hands-on electronic labs. The second iteration included knowledge checks embedded at various points in the videos resulting in increased learner engagement. The approach appears to provide better engagement. However, the use of both approaches adds variety which introduces a level of surprise and anticipation. Both approaches engage the students.

The latest surveys and previous ones consistently show that the flipped classroom approach is satisfactory for both online and traditional face-to-face delivery of instruction ${ }^{1-3}$. However, adding interactivity to the content gets students more involve with learning the content. Having students pull information to complete a learning activity is better than always pushing content to the learner. A variety of online assessment and interactive activities using H5P are available and will be tested in the future to minimize any student boredom and distractions. Combining the H5P suite of assessment and multimedia tools along with the principles and guidelines associated with Cognitive Load Theory will improve learning for courses. The systematic integration of evolving e-learning technologies and the recent Cognitive Load Theory shows promise to provide an enriched learning experience leading to lasting impact for the motivated learner.

\section{References.}

1. Santiago, John and Jing Guo, "Leveraging Internet Marketing Technologies and Green-Screen Techniques for Developing Engaging STEM and Online Content”, ASEE Rocky Mountain Section Conference, Cedar City, Utah, 2016

2. Guo, Jing and John Santiago, "Flipped Classroom Method in Teaching "Introduction to Engineering" Course Online, ASEE Rocky Mountain Section Conference, Cedar City, Utah, 2016

3. Guo, Jing, Kathy Kasley and John Santiago, "The Challenges of Teaching Engineering Labs Online”, ASEE Rocky Mountain Section Conference, Cedar City, Utah, 2016

4. Retrieved from https://h5p.org

5. Clark, Ruth, Frank Nguyen and John Sweller, "Efficiency in Learning - Evidence-Based Guidelines to Manage Cognitive Load, Pfeiffer. 2006

6. Clark, Ruth, Richard E. Mayer, "E-Learning and the Science of Instruction - Proven Guidelines for Consumers and Designers of Multimedia Learning, Third Edition, Pfeiffer, 2011

7. Carey, Benedict, "How We Learn - The Surprising Truth About When, Where, and Why It Happens", Random House, 2014

8. "Online Learning is Different, Harvard Study", retrieved from https://www.sciencedaily.com/releases/2013/04/130404122240.htm, Harvard University, April 4, 2013

9. Gutierrez, Karla, results from Brandon Study retrieved from http://info.shiftelearning.com/blog/bid/301248/15facts-and-stats-that-reveal-the-power-of-elearning?, (Brandon Hall Study http://www.brandon-hall.com), April 7, 2016

10. Ruedlinger, Ben, “Does Video Length Matter?”, May 7, 2012, retrieved from https://wistia.com/blog/does-length-matter-it-does-for-video-2k12-edition

11. Ethan Edwards, "6 Rules Designing elearning Maximum Motivation ebook” retrieved from http://learn.alleninteractions.com/learner-motivation-ebook

12. Christopher Pappas, "How to Use Interactive Videos in Online Training", retrieved from https://elearningindustry.com/tips-use-interactive-videos-online-training, October 24, 2016 
13. Pandey, Asha, Using Interactive Videos for Learner Engagement, https://elearningindustry.com/interactivevideos-for-learner-engagement, August 23, 2016

14. Pandey, Asha, Free eBook: How to Use Interactive Videos for Learner Engagement and Supercharge Your Online Training, March 7, 2017 